\title{
Instalasi Kabel Fiber Optic dan Perangkat Switch Untuk Layanan Internet Menggunakan Metode CWDM oleh PT. XYZ
}

\author{
Ahmad Syahrul Fardani, Indri Neforawati \\ Program Studi Teknik Multimedia dan Jaringan \\ Jurusan Teknik Informatika dan Komputer \\ Politeknik Negeri Jakarta \\ Depok, Indonesia \\ aruule.yurja91@gmail.com, indri.neforawati@tik.pnj.ac.id
}

Diterima: 22 April 2019. Disetujui: 19 Mei 2019 Dipublikasikan: Mei 2019

\begin{abstract}
Abstrak- Layanan internet adalah sebuah layanan dengan kecepatan tinggi berbasis teknologi VPN MPLS dengan lastmile fiber optic sehingga mampu memberikan kualitas layanan dan keamanan jaringan yang terbaik. Selain itu terdapat berbagai metode komunikasi. Salah satunya metode CWDM (Coarse Wavelength Division Multiplexing) yang merupakan salah satu teknologi WDM (Wavelength Division Multiplexing) yang memiliki channel spacing lebih lebar dibandingkan dengan teknologi WDM sebelumnya. Metode CWDM ini diimplementasikan sebagai pengembangan pada proses transmisi data guna mempercepat transfer data dan meningkatkan bandwidth. Selain menggunakan fiber optic dan metode CWDM untuk berkomunikasi, layanan internet juga menggunakan switch sebagai perangkat pendukung layanan tersebut. Dimana perangkat switch diletakkan pada sisi user dan dikonfigurasi dengan memberikan VLAN dan IP Address sesuai dengan alokasi yang dibutuhkan. Dalam hal ini penulis fokus untuk menganalisis hasil instalasi dari kabel fiber optic dan keunggulan metode CWDM serta hasil pengujian perangkat switch dengan melakukan monitoring melalui web speedtest dan menghasilkan bandwidth sebesar 50Mbps.
\end{abstract}

Kata Kunci : bandwidth; cwdm; fiber optic; internet; switch

\section{PENDAHULUAN}

Kebutuhan akan proses komunikasi melalui internet secara handal, cepat dan tepat, tentunya dapat mendorong kebutuhan akan bandwidth dan layanan yang terbaik. Sehingga user mencari layanan komunikasi jaringan internet yang sesuai dengan kebutuhannya. Salah satunya dengan memanfaatkan adanya penyedia jasa layanan jaringan komunikasi seperti PT. XYZ yang merupakan perusahaan yang bergerak dibidang jaringan komunikasi fiber optic. Dimana fiber optic merupakan salah satu media transmisi yang dapat menyalurkan informasi dengan kapasitas besar dan keandalan yang tinggi serta dapat dimanfaatkan sebagai sarana transmisi jarak jauh.

Selain pengunaan fiber optic sebagai media komunikasi, PT. XYZ menyediakan beberapa layanan instalasi, salah satunya instalasi untuk layanan internet yang merupakan layanan kecepatan tinggi berbasis teknologi VPN MPLS dengan lastmile fiber optic sehingga mampu memberikan kualitas layanan dan keamanan jaringan yang terbaik

PT XYZ menggunakan berbagai metode dalam proses instalasi, salah satunya yaitu metode CWDM (Coarse Wavelength Division Multiplexing) yang telah berkembang dari keterbatasan sistem transmisi serat optik pada metode yang diimplementasikan sebelumnya yaitu DWDM (Dense Wavelength Division Multiplexing), dimana metode CWDM ini digunakan untuk mengakomodasi lonjakan trafik metode DWDM sebesar 1,6 nm (nanometer) atau sekitar $200 \mathrm{GHz}$ dari sejumlah backbone yang meningkat sangat pesat sehingga dapat menampung kapasitas throughput yang besar yaitu sekitar 1 Tbs atau $1.000 \mathrm{Gbs}$, serta dapat menghemat penggunaan core dan meminimalisir pemasangan kabel baru pada saat penambahan user. Selain fiber optic dan CWDM sebagai media komunikasi, layanan internet juga menggunakan switch sebagai perangkat pendukung yang digunakan sebagai Central Connection Point, dimana sinyal-sinyal data dari 
server atau host akan disentralisir di dalam perangkat switch ini, yang kemudian akan menyalurkannya ke dalam jaringan user tersebut.

Switch dikonfigurasi untuk layanan internet dengan memberikan VLAN dan IP Address yang sesuai dengan alokasi yang dibutuhkan oleh user sehingga layanan yang diberikan dapat digunakan sesuai dengan permintaan. Maka dari itu permasalahan yang dihadapi adalah bagaimana meng-instalasi kabel fiber optic dan perangkat switch untuk layanan internet menggunakan metode CWDM.

\section{STUDI LITERATUR}

\section{A. Internet}

Dengan adanya internet dapat menghubungkan sekumpulan jaringan komputer secara fisik serta dapat membaca dan menguraikan berbagai protokol komunikasi yang biasa kita ketahui seperti Internet Protocol (IP) serta Transmission Control Protocol (TCP). Melalui protokol, dua atau lebih komputer dapat saling bertukar informasi. Salah satu keunggulan dari layanan internet yaitu memiliki kecepatan tinggi dengan berbasis teknologi VPN MPLS dengan lastmile fiber optic sehingga mampu memberikan kualitas layanan dan keamanan jaringan yang terbaik [9].

\section{B. POP (Point of Presence)}

Pada lingkungan penyedia jasa layanan internet (ISP), Point of Presence (POP) dikenal sebagai bagian infrastruktur terluar dari sebuah ISP yang terhubung ke titik ISP yang terdekat dari pelanggan, dalam POP tersebut terdapat sejumlah perangkat fisik yang memiliki tugas untuk melakukan pembuatan serta pemutusan sambungan yang biasa disebut titik terminasi atau demarkasi dari pelanggan dengan ISP yang digunakan. Infrastruktur POP berdasrkan model jaringan komputer berada pada bagian jaringan akses (access network), dimana berfungsi langsung sebagai penghubung dengan pelanggan atau bagian jaringan terdistribusi (distribution network) yang dapat mengintegrasikan beberapa access network pada sebuah ISP kedalam jaringan inti (core network)[8].

\section{Fiber Optic}

Diantara sistem komunikasi lainnya, komunikasi optik memiliki keunggulan yaitu dapat merubah informasi menjadi sinyal listrik, kemudian diubah lagi menjadi optik/cahaya. Dimana sinyal tersebut melewati jalur serat optik kemudian melakukan proses perubahan kembali dari cahaya menjadi sinyal listrik dan diterjemahkan menjadi suatu informasi. Lain halnya dengan sistem komunikasi biasa, dimana sinyal informasi diubah menjadi sinyal listrik/elektrik dan kemudian melewati kabel tembaga sampai ke tujuan lalu diubah kembali menjadi informasi yang sama seperti yang dikirimkan. Adapun 2 jenis serat optik antara lain [10] :

\section{a. SMF (Singlemode Fiber)}

Serat optik singlemode memiliki core yang kecil dan memiliki hanya satu jalur cahaya. Perbedaan antara indeks bias core dan cladding sangat kecil. SMF memiliki kapasitas yang lebih besar untuk mentransmisikan informasi karena dapat mempertahankan akurasi jumlah cahaya untuk jarak tempuh yang lebih besar dan tidak menunjukkan penyebaran cahaya yang disebabkan oleh beberapa mode. Atenuasi serat SMF juga lebih rendah bila dibandingkan dengan MMF. Kekurangan dari serat jenis ini adalah diameter core yang kecil yang membuat menyambungan cahaya ke dalam core lebih sulit, pembangunan yang sulit dan biaya yang relatif mahal.

\section{b. MMF (Multimode Fiber)}

Multimode fiber memiliki diameter core dan indeks bias relatif lebih besar daripada singlemode fiber dan memungkinkan sejumlah besar cahaya melewatinya. Ukuran core kabel multimode secara umum adalah berkisar antara 50 sampai dengan 100 mikrometer. Biasanya ukuran NA yang terdapat di dalam kabel multimode pada umumnya adalah berkisar antara 0,20 hingga 0,29. NA atau Numerical Aperture adalah ukuran kemampuan sebuah serat untuk menangkap cahaya, juga dipakai untuk mendefinisikan acceptance core dari sebuah serat optik. Jenis serat optik Multimode dapat dikategorikan menjadi dua macam yaitu serat optik multimode step index dan serat optik multimode gradded index

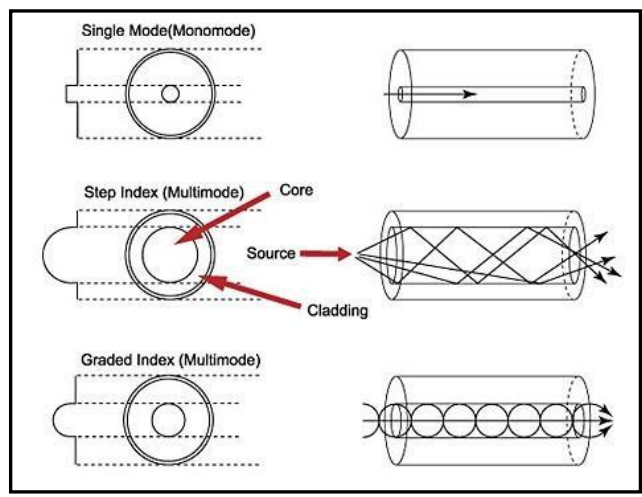

Gambar 1. Jenis-Jenis Fiber Optic

\section{Switch}

Perangkat dari jaringan komputer yang bekerja pada bagian OSI layer 2 (data link) dan sebagai penyambung data antara satu koneksi ke koneksi lainnya disebut switch. Adapun fungsi switch pada layer data link yaitu sebagai pengenal 
adanya MAC Addressing untuk memilah data mana saja yang harus dihubungkan. Selain itu switch dapat digunakan sebagai repeater, dapat sebagai penghubung kabel UTP antara satu komputer dengan komputer lainnya, serta di dalam switch terdapat routing yang fungsinya sebagai batu loncatan jaringan LAN untuk terkoneksi dengan komputer. Dari berbagai fungsi switch, tentunya dapat dimanfaatkan sesuai dengan kebutuhan untuk membuat kerja sistem menjadi lebih efektif dan efisien [11].

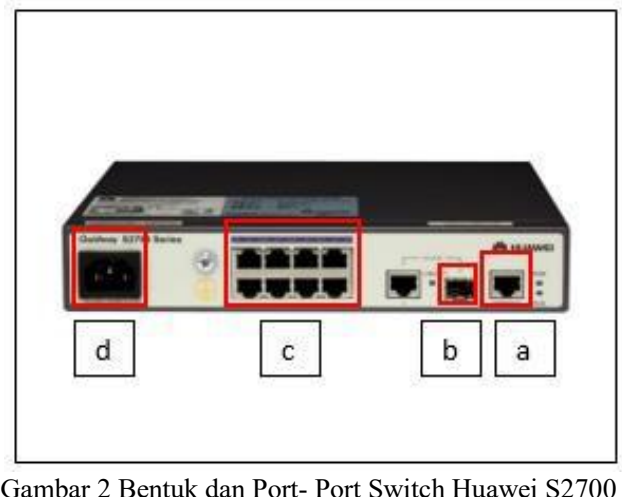

\section{E. CWDM (Coarse Wavelength Division Multiplexing)}

CWDM (Coarse Wavelength Division Multiplexing) merupakan salah satu teknologi WDM (Wavelength Division Multiplexing) yang memiliki channel spacing lebih lebar dibandingkan dengan DWDM. Berbeda dengan teknologi WDM lainnya, CWDM dapat menggunakan spektrum band yang lebih luas, tidak terbatas pada satu atau dua band saja serta dapat digunakan baik pada serat optik jenis multimode ataupun singlemode walaupun memiliki jarak jangkauan sinyal yang lebih pendek dibanding DWDM. Teknologi CWDM diimplementasikan sebagai pengembangan transport data pada proses transmisi guna mempercepat transfer data dan meningkatkan bandwidth [4].

Dalam prosesnya, sistem CWDM terdiri dari sekumpulan transmitter sebagai sumber optik yang memancarkan cahaya dengan panjang gelombang yang berbeda-beda yang merupakan bentuk sinyal dari berbagai layanan yang akan di transmisi-kan melalui serat optik. Sinyal akan mengalami proses multiplexing pada transmitter terlebih dahulu, kemudian di demultiplexing kembali dan dipisahkan berdasarkan panjang gelombangnya masing- masing pada sisi receiver [5].

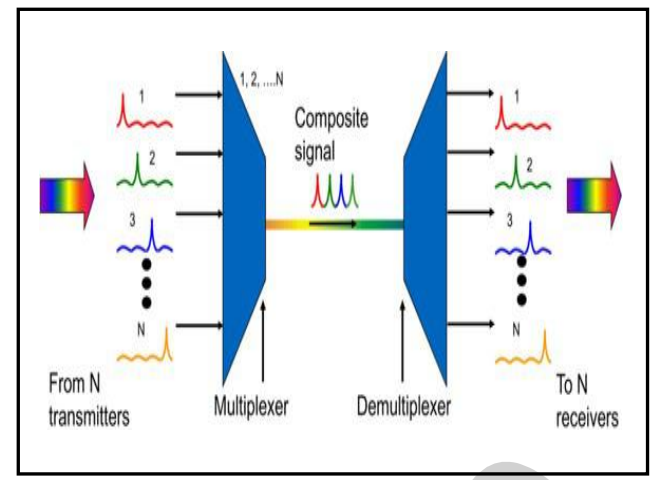

Gambar 3 Sistem CWDM Secara Umum

\section{F. ODF (OPTICAL DISTRIBUTION FRAME)}

Suatu frame yang memiliki struktur mekanik berupa rack atau shelf dengan fungsi utama sebagai tempat pegangan kabel (fiber) dan elemen passive lainnya (support mekanik) disebut dengan ODF (Optical Distribution Frame). ODF dapat melindungi elemen-elemen yang ada didalamnya karena dilengkapi dengan fiber organizer [1].

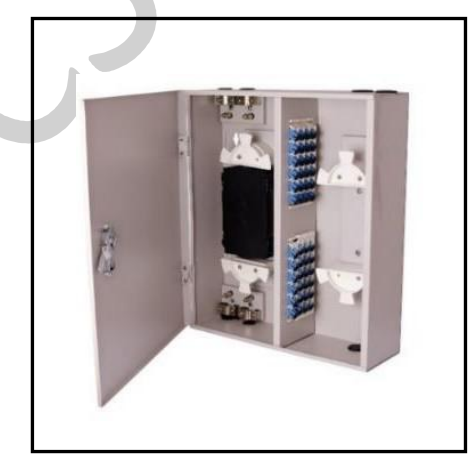

Gambar 4 ODF (Optical Distribution Frame)

\section{G. OTDR (Optical Time-Domain Reflectometer)}

Perangkat yang digunakan untuk pengukuran dan penemuan kesalahan pada kabel fiber optic disebut OTDR. Dimana teknik ini dapat secara luas digunakan untuk menyelidiki integritas dari link fiber optic dan menilai keseragaman dari kabel fiber optic itu sendiri [6].

Beberapa kegunaan dari OTDR dalam instalasi, operasi dan pemeliharaan pada jaringan kabel serat optik yaitu [3]:
a. Untuk uji
terima hasil
pembangunan
atau penggelaran kabel
serat optik.
b. Untuk memeriksa kualitas kabel serat optik yang beroperasi.
c. Untuk menganalisa jenis gangguan dan mengetahui jarak gangguan kabel serat optik. 


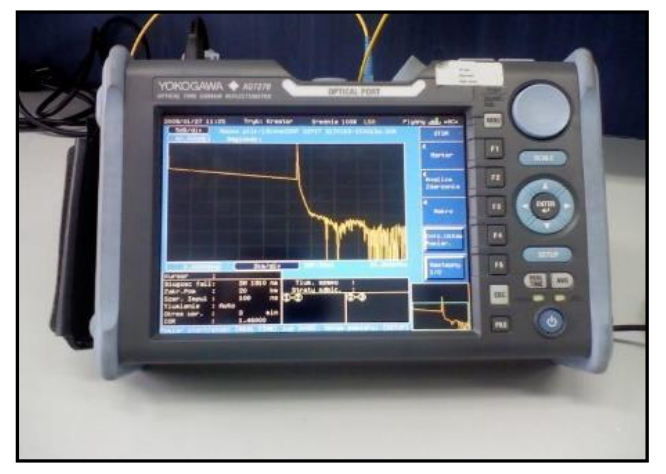

Gambar 5 OTDR (Optical Time-Domain Reflectometer)

\section{H. QoS (Quality of Service)}

QoS digunakan untuk mengukur sekumpulan atribut kinerja yang telah dispesifikasikan dan diasosiasikan dengan suatu service menggunakan metode pengukuran tentang seberapa baik jaringan dan suatu usaha untuk mendefinisikan bagaimana karakteristik dan sifat dari service tersebut. Terdapat parameter dari Quality of Service antara lain [14] :

\section{a. Throughput}

Throughput yaitu kecepatan (rate) transfer data efektif yang diukur dalam bps (bit per second). Throughput adalah jumlah total kedatangan paket yang sukses yang diamati pada tujuan selama interval waktu tertentu dibagi oleh durasi interval waktu tersebut.

\section{b. Packet Loss}

Packet Loss merupakan suatu parameter yang menggambarkan suatu kondisi yang menunjukkan jumlah total paket yang hilang dapat terjadi karena collision dan congestion pada jaringan.

c. Delay (Latency)

Delay (Latency) merupakan waktu yang dibutuhkan data untuk menempuh jarak dari asal ke tujuan. Delay dapat dipengaruhi oleh jarak, media fisik, congesti atau juga waktu proses yang lama.

d. Jitter atau Variasi Kedatangan Paket

Jitter diakibatkan oleh variasi-variasi dalam panjang antrian, dalam waktu pengolahan data, dan juga dalam waktu penghimpunan ulang paket-paket diakhir perjalanan jitter. Jitter lazimnya disebut variasi delay, berhubungan erat dengan latency, yang menunjukkan banyaknya variasi delay pada transmisi data di jaringan.

\section{Bandwidth}

Lebar cakupan frekuensi yang dipakai oleh sinyal dalam medium transmisi disebut bandwidth. Hasil dari bandwidth berupa suatu nilai konsumsi transfer data yang dihitung dalam bit/detik atau yang biasanya disebut dengan bit per second (bps), antara server dan client dalam waktu tertentu [12]. Terdapat 2 jenis Bandwidth yaitu [7] :

a. Bandwidth Analog

Bandwidth analog merupakan perbedaan antara frekuensi terendah dan frekuensi tertinggi dalam sebuah rentang frekuensi yang diukur dalam satuan $\mathrm{Hz}$ (hertz) yang dapat menentukan banyaknya informasi yang dapat ditransmisikan dalam suatu saat.

b. Bandwidth Digital

Bandwidth digital merupakan jumlah atau volume suatu data (dalam satuan bit per detik/bps) yang dapat dikirimkan melalui sebuah saluran komunikasi tanpa adanya distorsi.

\section{J. Throughput}

Throughput adalah bandwidth aktual, yang diukur dalam satuan waktu dan dalam kondisi jaringan yang digunakan untuk mentransfer file dengan ukuran tertentu. Contoh throughput, jika menggunakan internet pada bandwidth 5 Mbps, tetapi ingin mengunduh file dengan kecepatan 4,2 Mbps. Artinya, kecepatan asli dari proses transmisi tersebut merupakan throughput, dimana ukuran throughput lebih kecil dibandingkan dengan bandwidth [2].

\section{K. NMS (Network Monitoring Server)}

Network Monitoring System adalah sebuah proses pengumpulan dan pengukuran informasi yang berkaitan dengan layanan sebuah jaringan, proses monitoring dilakukan secara rutin, berkala, dan berulang-ulang agar dapat memantau setiap perubahan yang terjadi, sehingga secara hemat proses monitoring mampu menyajikan informasi tentang kondisi layanan jaringan secara real time, baik dari sisi perangkat maupun dari sisi kualitas yang diberikan. Akan tetapi apabila kebutuhan, penggunaan, dan infrastruktur jaringan meningkat, makaproses monitoring menjadi tidak mudah. Kemudian proses pemetaan untuk pencarian kerusakan yang menyebabkan menurunnya kualitas layanan jaringan juga akan membutuhkan banyak waktu Serta permasalahan lainnya yang berkaitan dengan keamanan, pengawasan, pengaturan, dan pemeliharaan jaringan yang jauh lebih rumit bila tidak memanfaatkan network monitoring system (NMS) yang dibangun secara sistematis [13].

\section{PERANCANGAN DAN IMPLEMENTASI}

\section{A. Tahapan Instalasi}

Proses instalasi ini dilakukan dengan cara pemberian surat perintah kerja kepada teknisi, survei lapangan, pengecekan letak CWDM, mempersiapkan alat-alat yang akan digunakan, instalasi kabel, jointing kabel, pengukuran rata-rata daya sinyal di ODF dan OTB, patching core, konfigurasi, test comissioning, pelabelan, dan pembuatan berita acara. Gambar 6 adalah alur kerja proses instalasi secara terperinci. 


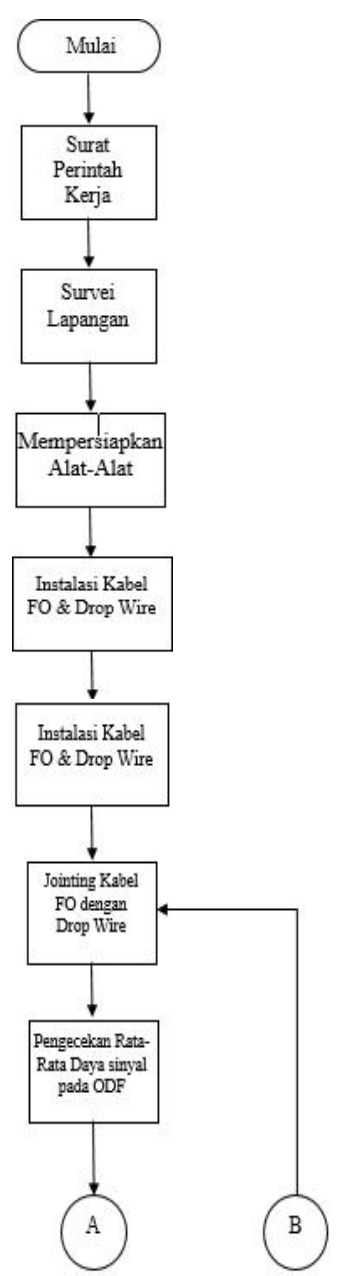

Gambar 7 Flowchart Instalasi Bagian 1

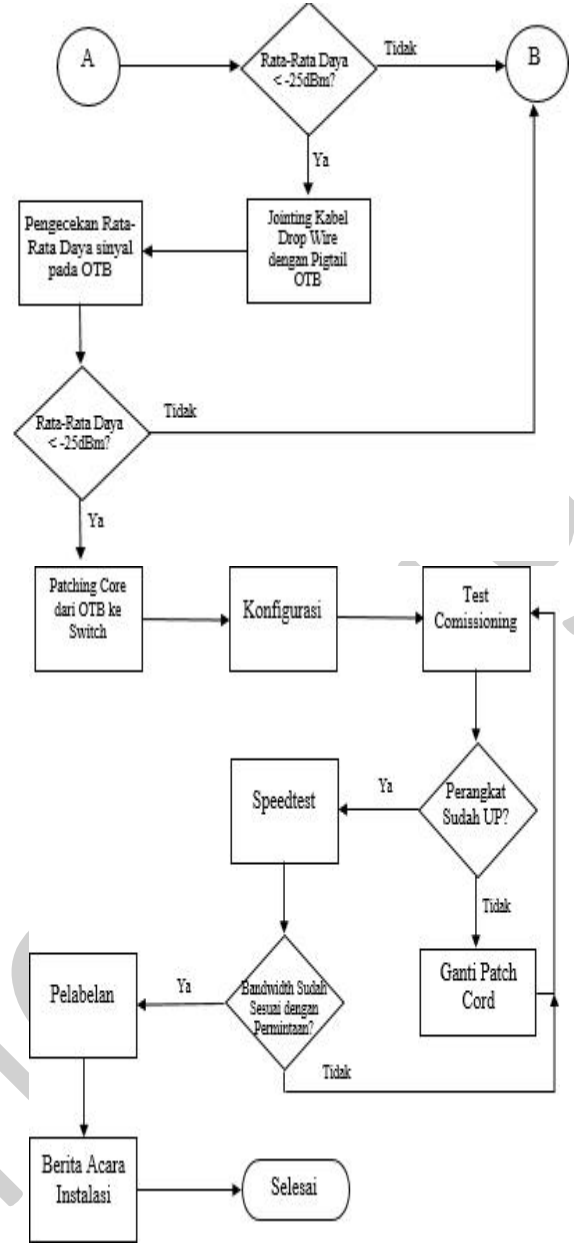

Gambar 6 Flowchart Instalasi Bagian 1 


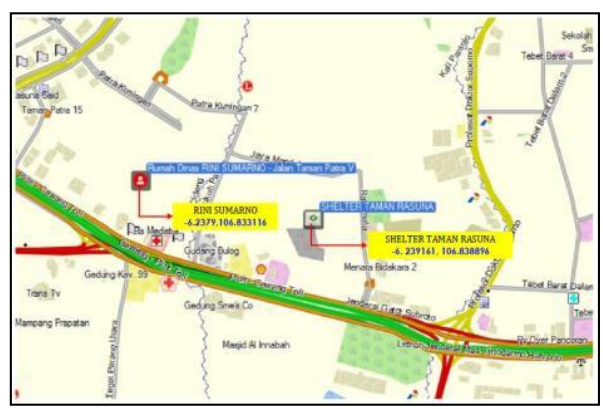

Gambar 8 Layout POP dan User

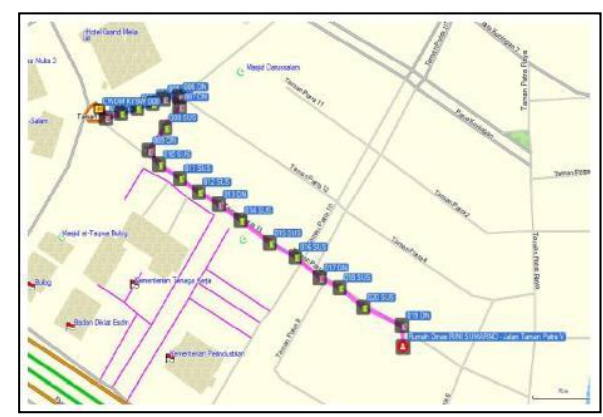

Gambar 9 Letak CWDM

\section{B. SPK (Surat Perintah Kerja)}

Surat perintah kerja diberikan oleh pihak PT. XYZ kepada PT. ABC untuk melaksanakan project instalasi pada user dan juga berfungsi sebagai perijinan masuk ke ruang server untuk team $\mathrm{ABC}$ yang bertugas melakukan proses instalasi.

\section{Survei Lapangan}

Survei lapangan perlu dilakukan untuk dapat mengetahui kondisi dari daerah yang akan dilakukan instalasi sehingga dapat menggunakan tipe kabel apa yang akan digunakan dan pengguna komponen apa saja yang diperlukan. Setelah melakukan survei lapangan, selanjutnya pembuatan as-planning survey yang isinya mengenai lokasi POP di Shelter Taman Rasuna untuk melakukan proses instalasi beserta titik koordinatnya, seperti yang ditunjukkan pada Gambar 8. Dalam proses survei, perlu melakukan pengecekan lokasi CWDM tujuannya agar mempermudah proses instalasi kabel fiber optic dari letak CWDM hingga sampai ke lokasi server. Perangkat CWDM tidak dilakukan instalasi karena bersifat existing, yang artinya bahwa bagian internal (PT. XYZ) yang melakukan instalasi. Setelah melakukan pengecekan, selanjutnya pembuatan as planning survey yang isinya mengenai lokasi CWDM menuju lokasi user untuk melakukan proses instalasi beserta titik koordinatnya, seperti yang ditunjukkan pada Gambar 9.

\section{Mempersiapkan Alat-Alat}

Setelah proses instalasi kabel selesai maka langkah selanjutnya yaitu melakukan proses instalasi, sebelum melakukan proses instalasi terlebih dahulu mempersiapkan alat-alat dan perangkat yang akan digunakan, adapun alat-alat dan perangkatnya yaitu sebagai berikut :

a. Switch Huawei S2700

b. Kabel Power

c. Kabel UTP (Unshield Twisted Pair)

d. Kabel Patch cord

e. Kabel Console

f. SFP (Small From-Factor)

g. OTDR (Optical Time-Domain Reflectometer)

h. OPM (Optical Power Meter)

i. Splicer Fusion

j. $\quad$ Cleaver Fiber Optic

k. Stripper Fiber Optic

1. Laptop

m. Print Label

\section{E. Instalasi Kabel FO dan Drop Wire}

Instalasi kabel yang pertama kali dilakukan yaitu kabel fiber optic dari letak CWDM menuju letak ODF. Tipe kabel fiber optic yang digunakan yaitu ADSS ZTT 6C 2019. Panjang kabel yang ditarik sesuai dengan planning yaitu $640 \mathrm{~m}$. Panjang kabel tersebut tidak boleh kurang karena dapat menyebabkan sinyal tidak sampai ke user. Proses instalasi kabel drop wire ditunjukkan pada Gambar 10

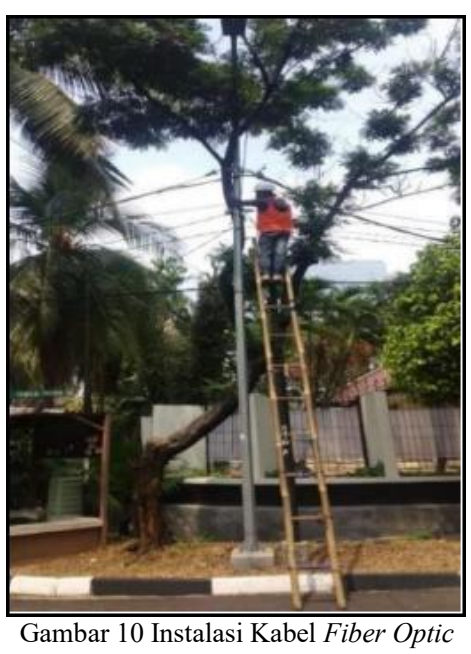

Instalasi kabel selanjutnya yaitu kabel drop wire dari letak ODF menuju ruang server. Tipe kabel drop wire yang digunakan yaitu drop wire 2 core. Adapun panjang kabel yang ditarik sesuai dengan planning yaitu $60 \mathrm{~m}$. Proses instalasi kabel drop wire dilakukan oleh tim tarik dan tim FOC (Fiber Optic Cable). Proses instalasi kabel drop wire ditunjukkan pada Gambar 11. 


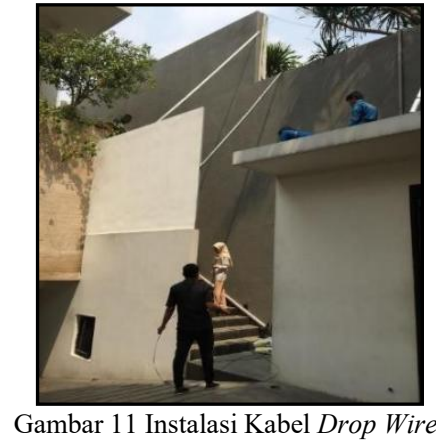

\section{F. Jointing Kabel FO dengan Drop Wire}

Proses ini dilakukan setelah instalasi kabel fiber optic dan drop wire selesai. Proses jointing ini dilakukan antara kabel fiber optic dari arah CWDM kearah letak ODF dengan kabel drop wire. Jointing dilakukan di ODF namun pigtail ODF tidak digunakan. Kabel fiber optic yang digunakan memiliki kapasitas 6 core tetapi yang di join dengan drop wire hanya 2 core saja karena sesuai dengan kapasitas core yang dimiliki oleh kabel drop wire tersebut. Gambar 12 menunjukkan hasil jointing pada ODF.

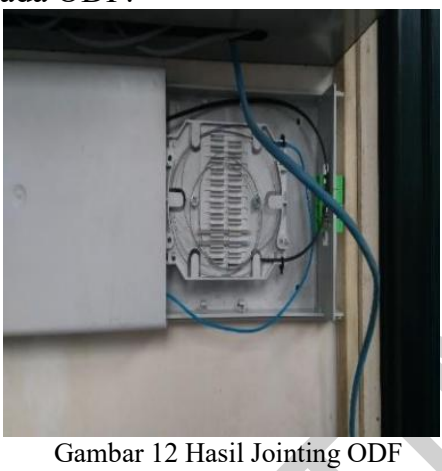

Gambar 12 Hasil Jointing ODF

G. Pengecekan Rata-Rata Daya Sinyal pada ODF

Standardisasi dari rata-rata daya sinyal yang dihasilkan yaitu minimal $-10 \mathrm{dBm}$ dan maksimal sampai $-25 \mathrm{dBm}$. Hasil pengukuran rata-rata daya sinyal pada ODF ditunjukkan pada Gambar 13.

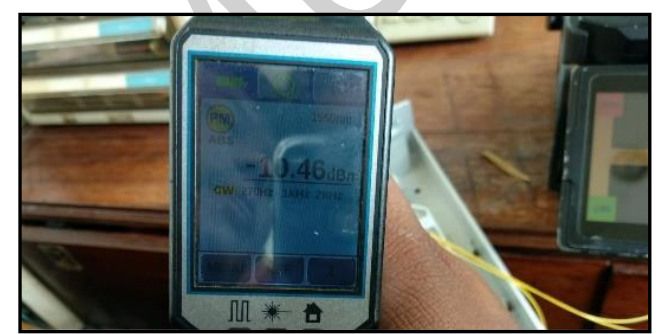

Gambar 13 Hasil Pengukuran Rata-Rata Daya Sinyal pada ODF

Pada display OPM menunjukkan hasil pengukuran dari rata-rata daya sinyal sebesar $10.46 \mathrm{dBm}$. Nilai tersebut dapat dikatakan sangat baik karena melewati batas minimal yaitu $-10 \mathrm{dBm}$ serta kurang dari batas maksimal yaitu $-25 \mathrm{dBm}$.

\section{H. Jointing Kabel Drop Wire dengan Pigtail}

Proses selanjutnya yaitu jointing kabel drop wire yang sudah berhasil ditarik sampai ke ruang server (indoor) dengan pigtail pada perangkat OTB. Proses jointing hanya menggunakan 2 kabel pigtail OTB dari kapasitas 6 pigtail karena menyesuaikan jumlah core pada kabel drop wire yang digunakan. Fungsinya agar membuat jalur dari arah POP melalui kabel fiber optic dan drop wire hingga masuk ke perangkat switch yang terletak pada ruang server. Gambar 3.8 menunjukkan hasil Jointing kabel drop wire dengan Pigtail OTB.

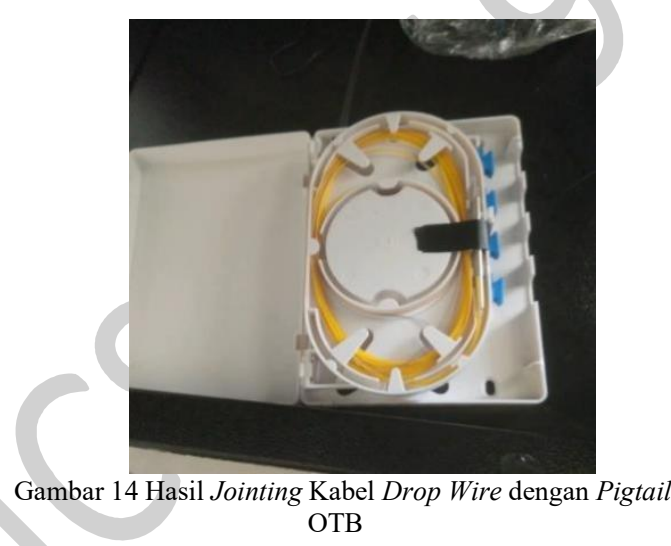

I. Patching Core dari OTB ke Switch

Tahapan selanjutnya yaitu patching core dari OTB ke switch menggunakan patch cord. Tujuannya yaitu agar OTB dan switch dapat saling terhubung satu sama lain. Adapun langkah-langkah nya adalah sebagai berikut ini :

a. Menghubungkan SFP single core ke port SFP pada perangkat switch.

b. Menghubungkan kabel patch cord ke SFP.

c. Menghubungkan perangkat switch dengan OTB menggunakan patch cord yang telah di hubungkan ke SFP pada perangkat switch.

Berikut hasil patching core dari OTB ke switch. Perangkat OTB berwarna putih dan kabel patch cord berwarna kuning. ditunjukkan pada Gambar 15.

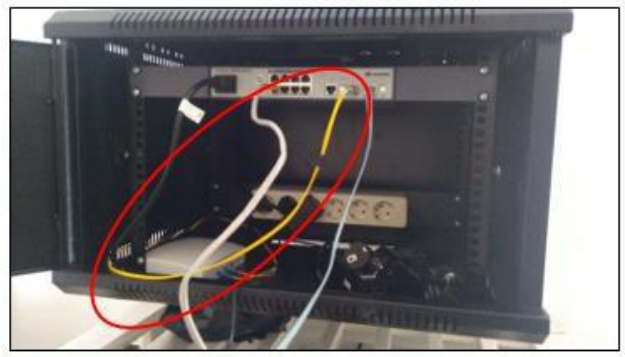

Gambar 15 Patching Core dari OTB ke Switch 


\section{J. Konfigurasi}

Proses Konfigurasi instalasi menggunakan software Putty yang sudah ter-instal di laptop dan terhubung ke perangkat switch S2700 menggunakan kabel console, berikut ini adalah konfigurasi yang dilakukan:

a. Command untuk mengganti nama perangkat $>$ system-view

>>sysname

JKT-TAMAN.RASUNA-

ASR920-

UPE-01

b. Membuat VLAN untuk NMS

>>vlan 13

$>>$ des NMS

$>$ quit

c. Membuat VLAN untuk layanan

>>vlan 83

$>>$ des internet.rini.sumarno

$>$ quit

d. Menambahkan IP address NMS pada VLAN

>>interface Vlanif 13

>>ip address 172.25.109.174 255.255.255.248

$>>$ undo shutdown

$>>$ quit

e. Menambahkan IP route

>>ip route-static 0.0.0.0 0.0.0.0 172.25.109.169

f. Membuka port untuk NMS

>>interface GigabitEthernet $0 / 0 / 1$

$>>$ description Trunk to JKT-

TAMAN.RASUNA- ASR920-UPE-01\#sho run interface eth $0 / 0 / 22$

$>>$ port link-type trunk

$>>$ port trunk allow-pass vlan 1383

$>$ quit

g. Membuka port untuk ke layanan

$>$ int Ethernet0/0/1

>>description 04000075856 Internet

Broadband Rini Sumarno Jalan Taman Patra

$\mathrm{V}$, Kuningan, Jakarta Selatan

$>>$ port link-type access

$>>$ port default vlan 83

$>>$ quit

>>user-interface vty 04

$>>$ authentication-mode aaa

>> user privilege level 15

$>>$ idle-timeout 300

$>>$ quit

h. Mengaktifkan telnet dan stelnet yang berfungsi melakukan remote di perangkat user sebagai berikut $\mathrm{L}$

$>>$ telnet server enable

>>stelnet server enable

\section{K. Test Commisioning}

Setelah konfigurasi selesai maka perlu melakukan test terhadap perangkat switch. Adapun proses nya dengan test ping yang dilakukan untuk menguji konektivitas apakah jalur sinyal tersebut sudah terhubung atau belum antara perangkat switch ke port Ethernet pada laptop menggunakan kabel UTP. Test ping dilakukan di Command Prompt (CMD) dengan terlebih dahulu memasukkan IP address user. Pengaturan IP ditunjukkan pada Gambar 16.

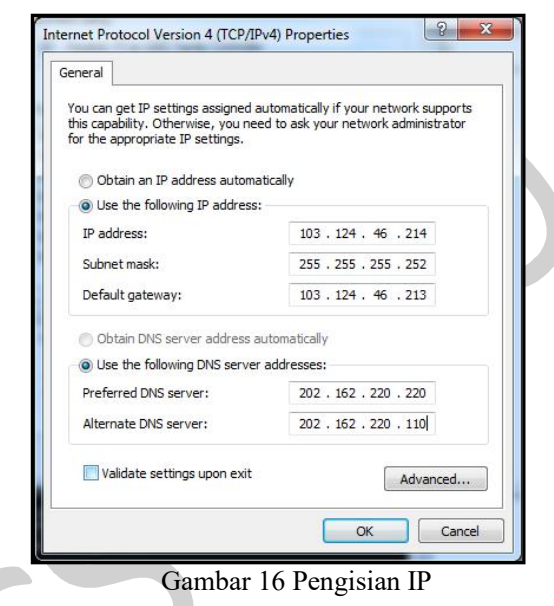

IP tersebut diberikan pihak PT. XYZ. Adapun IP address yang digunakan yaitu 103.124.46.214 dan gateway yang digunakan yaitu 103.124.46.213. Dimana 103.124.46 network ID, 213 merupakan host ID. Subnetmask yang digunakan yaitu 255.255.255.252. Serta DNS server yang diberikan yaitu 202.162.220.220 dan alternatif DNS nya yaitu 202.162.220.110. Selanjutnya mengecek apakah IP tersebut sudah terkonfigurasi sesuai dengan apa yang diinginkan yaitu dengan memasukkan perintah ipconfig pada CMD. Test ping ke IP gateway yaitu 103.124.46.213. adapun hasil test ping ditunjukkan pada Gambar 17.

\section{Speedtest}

Pengujian lainnya yaitu menggunakan web platform speedtest dari PT. XYZ. Tujuannnya untuk memonitor traffic bandwidth pada perangkat user. Adapun hasil dari pengujian bandwidth server ditunjukkan pada Gambar 18. 


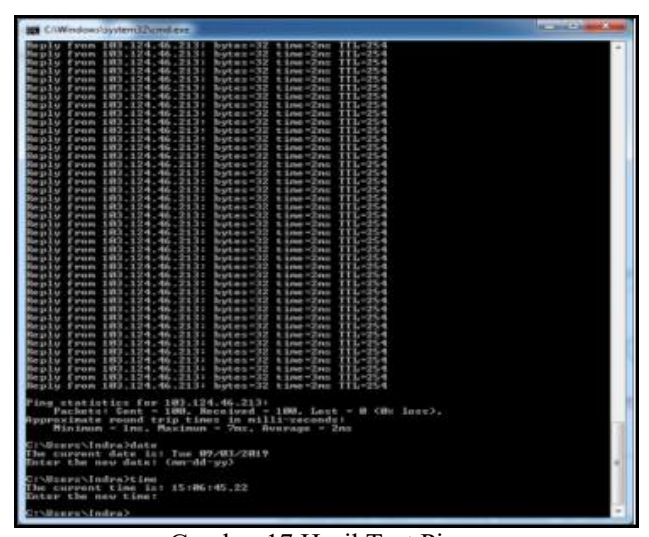

Gambar 17 Hasil Test Ping

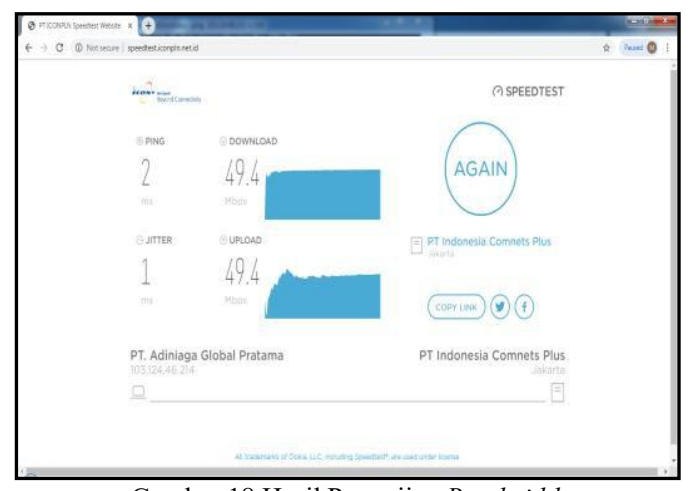

Gambar 18 Hasil Pengujian Bandwidth

Hasil pengujian bandwidth terhadap kedua server tersebut sesuai dengan permintaan user. Dimana user meminta pemasangan internet dengan kecepatan 50Mbps untuk proses download maupun upload. Hasil diatas dikatakan normal karena menunjukkan range angka $49 \mathrm{Mbps}$ mendekati angka 50Mbps. Penyebab bandwidth yang tidak sesuai dengan permintaan user biasanya karena masalah redaman (rugi-rugi) / loss signal pada kabel fiber optic saat melakukan proses jointing, atau kemungkinan lain yaitu power adapter yang dimiliki oleh server tidak sesuai dengan layanan yang diberikan. Dimana server di handle langsung oleh internal PT. XYZ, sehingga tim $\mathrm{ABC}$ tidak bisa memantau langsung server tersebut. Tapi secara keseluruhan perangkat sudah berperoperasi sesuai dengan permintaan user.

\section{Pelabelan}

Setelah tahapan pengujian bandwidth selesai, maka proses selanjutnya yaitu pelabelan dengan tujuan untuk memberikan semacam tanda/identitas pada perangkat maupun kabel agar mempermudah ketika terjadi trouble pada perangkat. Pelabelan ini terdapat data port atau sambungan dari patch cord ataupun kabel fiber optic yang digunakan. Pada Gambar 19 menunjukkan label pada OTB yang ditandai pada kotak berwarna merah.

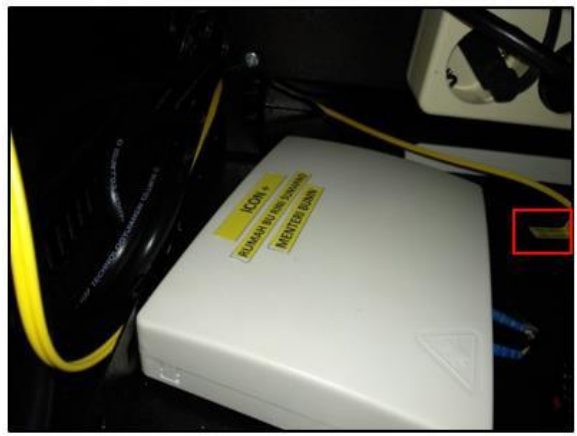

Gambar 19 Label pada Perangkat OTB

a. Label pada OTB

*R01_ODF01://01

$>$ R01_CON01://09

Keterangan : core 1 di OTB yang berada pada rak 1 terhubung dengan port 1 pada switch yang berada pada rak 1. Pada Gambar 20 menunjukkan label pada switch yang ditandai pada kotak berwarna merah.

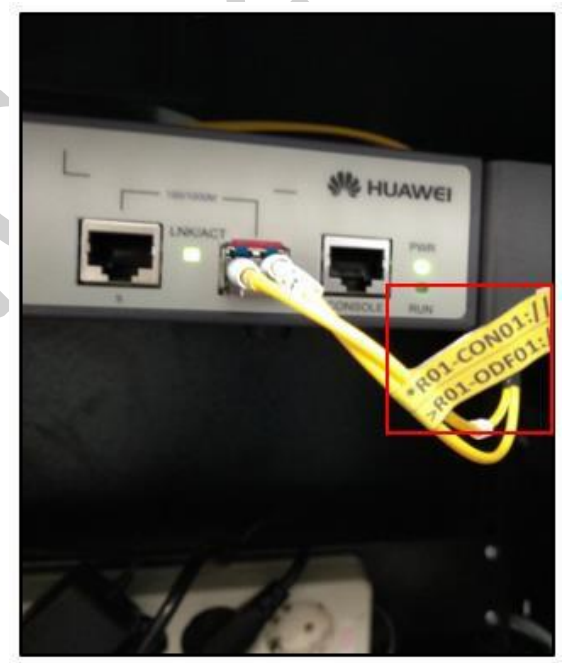

Gambar 20 Label pada Perangkat Switch

b. Label pada Switch

*R01_CON01://09

$>$ R01_ODF01://01

Keterangan : port 1 pada switch yang ada di rak 1 terhubung dengan core 1 di OTB yang berada pada rak 1.

\section{N. BAI (Berita Acara Instalasi)}

Tahap yang terakhir pada instalasi yaitu pembuatan BAI (Berita Acara Instalasi). BAI merupakan syarat bahwa instalasi telah selesai dilakukan sesuai dengan kualifikasi pemesanan layanan yang diminta oleh user.

\section{HASIL DAN PEMBAHASAN}

\section{A. QoS (Quality of Service)}

Quality of Service merupakan metode pengukuran yang digunakan untuk menetukan 
kemampuan sebuah jaringan seperti aplikasi jaringan, host, atau router dengan tujuan untuk memberikan service yang lebih baik dan terencana sehingga hasilnya dapat memenuhi kebutuhan suatu layanan yang dipinta oleh pelanggan. Berikut adalah hasil QoS dari proses instalasi.

TABEL I DATA DAN INFORMASI PROSES INSTALASI

\begin{tabular}{|c|c|c|c|c|c|}
\hline Tanggal Instalasi & $:$ & \begin{tabular}{|l} 
6 SEPTEMBER \\
2019
\end{tabular} & Tanggal Testcomm & $:$ & $\begin{array}{l}\text { 6 SEPTEMBER } \\
2019\end{array}$ \\
\hline Nama POP & : & $\begin{array}{l}\text { SHELTER } \\
\text { TAMAN } \\
\text { RASUNA }\end{array}$ & Nama Pelanggan & : & $\begin{array}{l}\text { RUMAH } \\
\text { MENTRI } \\
\text { BUMN }\end{array}$ \\
\hline Koordinat GPS & : & $\begin{array}{l}-6.239161, \\
106.838896\end{array}$ & Koordinat GPS & : & $\begin{array}{l}-6.237484, \\
106.832962\end{array}$ \\
\hline Type Perangkat & $:$ & MGS3520 & Type Perangkat & $:$ & S2700 \\
\hline Merk Perangkat & $:$ & ZYXEL & Merk Perangkat & $:$ & HUAWEI \\
\hline Serial Number & $:$ & Existing & Serial Number & $:$ & $\begin{array}{l}210235234010 \mathrm{~K} \\
4001170\end{array}$ \\
\hline Nama Instalasi & $:$ & Testcomm & Vendor Instalasi & $:$ & $\begin{array}{l}\text { PT Gerbang } \\
\text { Sinergi Prima }\end{array}$ \\
\hline
\end{tabular}

TABEL II HASIL QUALITY OF SERVICE

\begin{tabular}{|c|c|c|c|c|}
\hline \multirow{2}{*}{ Pengetesan } & \multirow{2}{*}{$\begin{array}{c}\text { Nilai Acuan / } \\
\text { Minimal }\end{array}$} & \multicolumn{2}{|c|}{ Hasil Test } & \multirow{2}{*}{ Catatan } \\
\hline & & OK & NOK & \\
\hline \multicolumn{5}{|l|}{ INTERNET } \\
\hline Bandwith Test & $\begin{array}{l}\text { Speedtest dan } \\
\text { upload, download } \\
\text { test }\end{array}$ & OK & & $\begin{array}{l}\text { Mengecek bandwidth menggunakan } \\
\text { web speedtest pada server lokal dan } \\
\text { interlokal, hasilnya } 49 \mathrm{Mbps}\end{array}$ \\
\hline $\begin{array}{l}\text { Round Trip atau } \\
\text { Delay (Latency) }\end{array}$ & $<10 \operatorname{ms}(\max )$ & OK & & $\begin{array}{l}\text { Mengrim paket } 32 \text { bytes ke POP } \\
\text { tempat pelanggan terhubung } \\
\text { menggunakan metode } \text { Ping standar }\end{array}$ \\
\hline Throughput & $90 \%$ dari bandwidth & OK & & \multirow[t]{2}{*}{$\begin{array}{l}15 \text { menit dilanjutkan dengan } 1 \text { kanal } \\
\text { yang mewakili selama } 24 \text { jam }\end{array}$} \\
\hline Packet LOSS & $<0,2 \%$ & OK & & \\
\hline \multicolumn{5}{|l|}{ FIBER OPTIC } \\
\hline $\begin{array}{l}\text { Splicing/Jointing } \\
\text { Bidirectional }\end{array}$ & $\begin{array}{l}\text { Redaman } \leq 0.05 \mathrm{~dB} \\
\text { per splice }\end{array}$ & $\mathrm{OK}$ & & $\begin{array}{l}\text { Rata-rata hasil splicing/jointing } \\
\text { core sebesar } \leq 0.05 \mathrm{~dB}\end{array}$ \\
\hline $\begin{array}{l}\text { OTDR } 2 \text { Arah } \\
\text { (lamda } 1310 \mathrm{n} / \mathrm{m} \\
\text { dan } 1550 \mathrm{n} / \mathrm{m} \text { ) }\end{array}$ & $\begin{array}{l}\text { Attenuation level } \\
\text { tidak lebih dari } 0.05 \\
\mathrm{~dB} / \mathrm{km}\end{array}$ & $\mathrm{OK}$ & & $\begin{array}{l}\text { Mengecek hasil redaman } \\
\text { berdasarkan jalur yang dilalui } \\
\text { menggunakan OTDR, rata-rata } \\
\text { hasil yang diperoleh sebesar } 0.05 \\
\mathrm{~dB} / \mathrm{km}\end{array}$ \\
\hline
\end{tabular}

\section{KESIMPULAN}

Dari hasil rancangan dan implementasi proses instalasi kabel fiber optic dan perangkat switch menggunakan metode CWDM yang telah dilakukan maka didapatkan kesimpulan sebagai berikut:

a. Tahapan pertama dalam proses instalasi yaitu melakukan survei lapangan terlebih dahulu dan mengumpulkan informasi serta data-data penting sebanyak-banyaknya, kemudian digambarkan sebagai dokumen ASPLAN (AsPlanning) yang salah satu isinya merupakan rute dan jalur kabel fiber optic dari letak POP melewati perangkat CWDM hingga sampai ke sisi user.

b. Pengecekan letak perangkat CWDM yang sudah ada (existing) perlu dilakukan untuk mengetahui jalur dari kabel fiber optic yang digunakan. Sehingga dapat mempermudah proses instalasi kabel fiber optic.

c. Metode CWDM digunakan untuk mengakomodasi lonjakan trafik dari sejumlah backbone yang meningkat sangat pesat sehingga dapat menampung kapasitas bandwidth yang besar, serta dapat menghemat penggunaan core dan meminimalisir pemasangan kabel baru pada saat penambahan user.

d. Proses instalasi kabel terdiri dari 2 tahapan, yang pertama instalasi kabel fiber optic dari letak CWDM sampai ke letak perangkat ODF, dimana panjang kabel yang digunakan yaitu $660 \mathrm{~m}$, dan yang kedua instalasi kabel drop wire dari letak ODF hingga ke ruang server yang letaknya ada di dalam Rumah tersebut. Panjang kabel drop wire yang digunakan sekitar 60m, kabel ini khusus untuk instalasi indoor.

e. Proses jointing kabel harus dilakukan secara teliti dan rapih sesuai SOP sehingga hasil redaman / loss signal yang didapatkan $\leq 0.05$ $\mathrm{dB}$.

f. Pengecekan hasil rata-rata daya sinyal pada ODF dan OTB sesuai standard, karena keduanya memiliki hasil rata-rata daya sinyal yaitu $-10.46 \mathrm{dBm}$ setelah diukur menggunakan OPM.

g. Konfigurasi pada perangkat switch menggunakan dua VLAN, VLAN yang pertama untuk NMS dan VLAN yang kedua untuk layanan. IP address untuk NMS yaitu 172.25.109.174 dan IP address untuk layanan yaitu 172.25.109.169.

h. Instalasi yang dilakukan dapat berhasil apabila terpenuhinya 3 syarat yaitu lampu indikator dari perangkat berwarna hijau, hasil test ping 
berhasil $100 \%$ yang artinya jalur tersebut sudah terhubung satu sama lain, dan yang terakhir yaitu menggunakan web paltform speedtest untuk mengetahui hasil throughput dan bandwidth yang didapatkan oleh user, jika sesuai dengan permintaan maka tahapan instalasi sudah selesai.

i. Pembuatan Berita Acara Instalasi dan hasil QoS (Quality of Service) sangat di perlukan, tujuannya sebagai laporan kepada user bahwa proses instalasi telah selesai dilaksanakan dan hasil nya sesuai dengan permintaan $u$ ser.

\section{DAFTAR REFERENSI}

[1] Amal, Hamka Ikhasul. 2015. "Analisis Pengujian Implementasi Perangkat Fiber To the Home (Ftth)". Bandung: Telkom Univesity.

[2] Asfihan, Akbar. 2019. Throughput adalah: Cara Kerja dan Opsi-opsi untuk Meningkatkan Throughput. https://adalah.co.id/throughput/. [22 November 2019].

[3] Dina, R. 2015. "Teknik Penyambungan Serat Optik Dengan Metode Penyambungan Fusi". Jurnal Penyambungan FO, Vol.8, No.1. Hal 1-5. Malang: Politeknik Negeri Malang.

[4] Febrianto, Andreas Ardian. 2009. COARSE WAVELENGTH DIVISIONMULTIPLEXING (CWDM).https://docplayer.info/37968064-Coarsewavelength-division-multiplexing-cwdm-andreas- ardianfebrianto-intisari.html. [11 November 2019].

[5] Hardiyana, I. 2012."Analisis Perencanaan Sistem Transmisi Serat Optik CWDM Jaringan Universitas Indonesia Terpadu (Juita)". Depok: Teknik Elektro Fakultas Teknik Universitas Indonesia.

[6] Liokumovich, L. B. et al. 2015. "Fundamentals of Optical Fiber Sensing Schemes Based on Coherent Optical Time Domain Reflectometry: Signal Model Under Static Fiber Conditions". Journal of Lightwave Technology, 33(17), 3660-3671.

[7] Mujiono.2012.PengertianBandwidth.http://www.teo rikomputer.com/2012/12/pengertian- bandwidth.html. [22 November 2019].

[8] OnnoWiki. 2011. Point of Presence http://onnocenter.or.id/wiki/index.php/Point_of_Pre sence. [8 November 2019].
[9] Pambudi, Edu. 2015. 24 Pengertian Internet menurut Para Ahli. https://dosenit.com/jaringankomputer/internet/pengertian-internet-menurut-ahli. [8 November 2019].

[10] Riadi, Muchlisin. 2018. Pengertian, Jenis dan Prinsip Kerja Serat Optik.https://www.kajianpustaka.com/2018/07/pengerti an- jenis-dan-prinsip kerja serat-optik.html. $\quad[10$ November 2019].

[11] Rifzan. 2018. Pengertian Switch, Hub dan Repeater beserta fungsinya. https://www.robicomp.com/pengertian-switch-hubdan-repeater-beserta fungsinya.html. $[20$ November 2019].

[12] Sora, N. 2015. Pengertian Bandwidth dan Fungsinya Secara Jelas. http://www.pengertianku.net/2015/05/pengertianbandwidth-dan-fungsinya.html. [22 November 2019]

[13] Wicaksono, Arief Ikhwan. 2018. “ANALISIS DAN IMPLEMENTASI NETWORK MONITORING SYSTEM (NMS) MENGGUNAKAN CACTI PADA LAYANAN INTERNET STMIK JENDERAL ACHMAD YANI YOGYAKARTA". Jurnal TEKNOMATIKA. Vol. 10, No. 2, JANUARI 2018. Yogyakarta.

[14] Wulandari, Rika. 2016. "ANALISIS QoS (QUALITY OF SERVICE) PADA JARINGAN INTERNET (STUDI KASUS : UPT LOKA UJI TEKNIK PENAMBANGAN JAMPANG KULON - LIPI)". Jurnal Teknik Informatikadan Sistem Informasi. Vol.2 No.2. Sukabumi. 